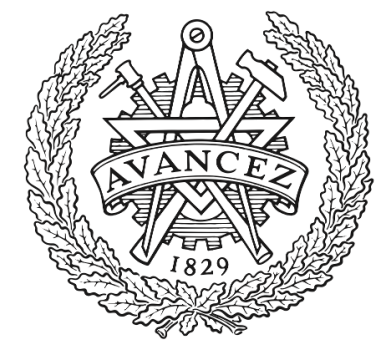

CHALMERS

UNIVERSITY OF TECHNOLOGY

\title{
Metal-Organic Frameworks with Hexakis(4-carboxyphenyl)benzene: Extensions to Reticular Chemistry and Introducing Foldable Nets
}

Downloaded from: https://research.chalmers.se, 2023-04-26 12:25 UTC

Citation for the original published paper (version of record):

Amombo Noa, F., Grape, E., Brülls, S. et al (2020). Metal-Organic Frameworks with Hexakis(4-carboxyphenyl)benzene: Extensions to Reticular Chemistry and Introducing Foldable Nets. Journal of the American Chemical Society, 142(20): 9471-9481. http://dx.doi.org/10.1021/jacs.0c02984

N.B. When citing this work, cite the original published paper. 


\section{Metal-Organic Frameworks with Hexakis(4- carboxyphenyl)benzene: Extensions to Reticular Chemistry and Introducing Foldable Nets}

Francoise M. Amombo Noa, ${ }^{*}$ Erik Svensson Grape, Steffen M. Brülls, Ocean Cheung, Per Malmberg, A. Ken Inge, Christine J. McKenzie, Jerker Mårtensson, and Lars Öhrström*

Cite This: J. Am. Chem. Soc. 2020, 142, 9471-9481

Read Online

ABSTRACT: Nine metal-organic frameworks have been prepared with the hexagon-shaped linker 1,2,3,4,5,6-hexakis(4-carboxyphenyl)benzene $\left(\mathrm{H}_{6} \mathrm{cpb}\right)$ by solvothermal reactions in dimethylformamide (dmf) or dimethylacetamide (dmac) with acetic acid or formic acid as modulators: $\left[\mathrm{Bi}_{2}(\mathrm{cpb})(\text { acetato })_{2}(\mathrm{dmf})_{2}\right] \cdot 2 \mathrm{dmf}$ CTH-6 forms a rtlnet; $2\left(\mathrm{H}_{2} \mathrm{NMe}_{2}\right)\left[\mathrm{Cu}_{2}(\mathrm{cpb})\right]$ CTH-7 forms a kgd-net; $\left[\mathrm{Fe}_{4}(\mathrm{cpb})\right.$ (acetato $\left.)_{2}(\mathrm{dmf})_{4}\right]$ CTH-8 and $\left[\mathrm{Co}_{4}(\mathrm{cpb})(\text { acetato })_{2}(\mathrm{dmf})_{4}\right]$ CTH-9 are isostructural and form yav-nets; $2\left(\mathrm{HNEt}_{3}\right)\left[\mathrm{Fe}_{2}(\mathrm{cpb})\right]$ CTH-10 and the two polymorphs of $2\left(\mathrm{H}_{2} \mathrm{NMe}_{2}\right)\left[\mathrm{Zn}_{2}(\mathrm{cpb})\right] \cdot 1.5 \mathrm{dmac}, \mathrm{Zn}$ MOF-888 and CTH-11, show kgd-nets; $\left[\mathrm{Cu}_{2}(\mathrm{cpb})\right.$ (acetato $\left.)_{2}(\mathrm{dmf})_{2}\right] \cdot 2 \mathrm{dmf}$, CTH-12, forms a mixed coordination and hydrogen-bonded sql-net; and $2\left(\mathrm{H}_{2} \mathrm{NMe}_{2}\right)\left[\mathrm{Zn}_{2}(\mathrm{cpb})\right]$ CTH-13, a

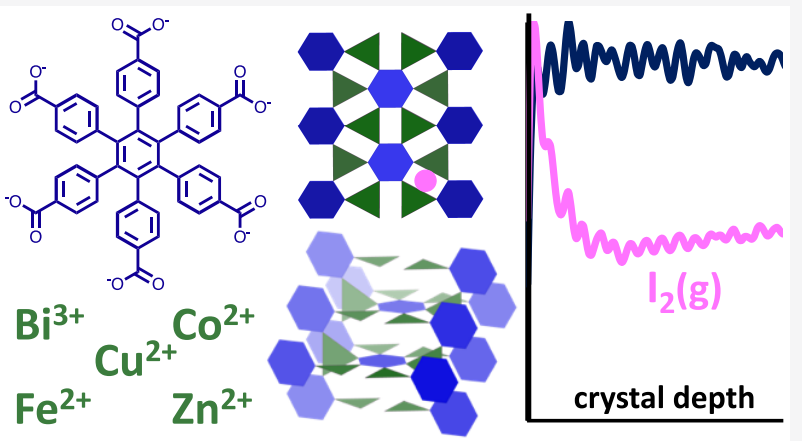
similarly mixed yav-net. Surface area values (Brunauer-EmmettTeller, BET) range from $34 \mathrm{~m}^{2} \mathrm{~g}^{-1}$ for CTH-12 to $303 \mathrm{~m}^{2} \mathrm{~g}^{-1}$ for CTH-9 for samples activated at $120{ }^{\circ} \mathrm{C}$ in dynamic vacuum. All compounds show normal (10-fold higher) molar $\mathrm{CO}_{2}$ versus $\mathrm{N}_{2}$ uptake at $298 \mathrm{~K}$, except the 19-fold CO $\mathrm{CO}_{2}$ uptake for CTH-12 containing $\mathrm{Cu}(\mathrm{II})$ dinuclear paddle-wheels. We also show how perfect hexagons and triangles can combine to a new $3 \mathrm{D}$ topology laf, a model of which gave us the idea of foldable network topologies, as the laf-net can fold into a 2D form while retaining the local geometry around each vertex. Other foldable nets identified are cds, cds-a, ths, sqc163, clh, jem, and tfc covering the basic polygons and their combinations. The impact of this concept on "breathing" MOFs is discussed. $\mathrm{I}_{2}$ sorption, both from gas phase and from $\mathrm{MeOH}$ solution, into CTH-7 were studied by time of flight secondary ion mass spectrometry (ToF-SIMS) on dried crystals. $\mathrm{I}_{2}$ was shown to have penetrated the crystals, as layers were consecutively peeled off by the ion beam. We suggest ToF-SIMS to be a method for studying sorption depth profiles of MOFs.

\section{INTRODUCTION}

Reticular chemistry is not a subdiscipline dealing with particular types of materials; it is a way of thinking of netforming building blocks and the networks they form in the solid state. ${ }^{1,2}$ The results of reticular chemistry are thus used to design metal-organic frameworks ${ }^{3}$ (MOFs), zeolites, or covalent-organic frameworks (COFs), ${ }^{4}$ but also to understand, and communicate, any network-forming chemical system through network topology analysis. ${ }^{5}$ Such materials may in addition be allotropes of the elements, polymorphs of ice, Zintl phases, and supramolecular systems. ${ }^{4}$ Here we report a significant extension in hexagon-based reticular chemistry, both theoretically and experimentally, using nine new MOFs (Figure 1).

These analyses are important, as reticular chemistry not only provides blueprints for these framework-type materials but also systematizes them, meaning we can incorporate results in a broader scientific context. For example, polymorphs of ice and allotropes of the group 14 elements are seldom discussed together but share both the basic tetrahedral building unit and the resulting network topologies. ${ }^{6}$ A more formal approach to these systems also allows for the use of AI and machine learning in the discovery and analysis of network-forming materials. $^{7,8}$

Network topologies may also be directly related to physical properties, such as mechanical anisotropy, giving, for example, large negative thermal expansion behavior. ${ }^{9,10}$ We here introduce foldable network topology, a concept that will increase the usefulness of reticular chemistry in the design of physical properties of materials.

Received: March 17, 2020

Published: April 21, 2020 


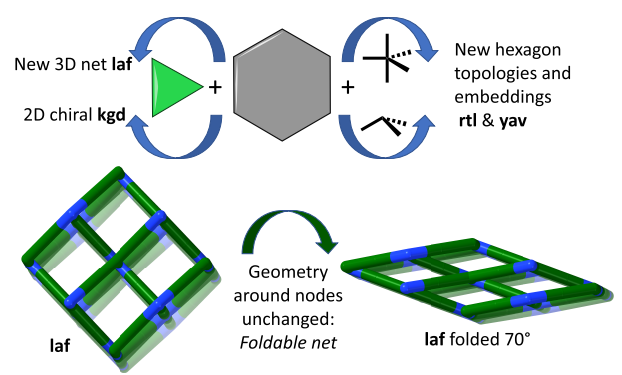

Figure 1. Reticular chemistry of hexagon-based MOF nets is expanded (top) and the concept of foldable network topology is introduced, the new 6- and 3-connected laf-net being one example (bottom).

An intriguing problem when dealing with periodic networks is how to combine well-known geometrical shapes into 3periodic networks. ${ }^{11}$ Knowing these construction principles are of paramount importance if we shall ever reach a level of "designing" molecule-based materials in the true sense of crystal engineering.

This is an old research question, with solutions already provided for many shapes in the work of Wells ${ }^{12}$ and Robson ${ }^{13}$ on network topologies, Fischer and Koch ${ }^{14}$ on sphere packings, and the mathematical formulation by O'Keeffe and DelgadoFriedrich. ${ }^{15-17}$ However, it transpires that while a large variety of combinations and resulting topologies can be found for most basic shapes, this is not the case for the hexagon. The Cambridge Structural Database (CSD) has been systematically explored for the topology of coordination polymers ${ }^{8}$ (the broader term of which MOFs is a subclass), and compounds with hexatopic hexagonal building blocks are very rare; only a handful of topologies are known. ${ }^{11}$

Thus, the hexagon shape has only two reported combinations with 3-connected nodes (the nets cys and dnf, the latter three-nodal ${ }^{18,19}$ ) and one each with the square pyramid (nts), the square (she), the hexagon itself ( $\mathbf{h x g}$ ), and the triangular prism (htp). Surprisingly, there are none with either the ubiquitous octahedron or the tetrahedron, nor with a perfect triangle. However, this is not due to a problem with higher connectivity vertices not being able to combine with the hexagon, as one of the very few known hexagon-based nets forms between the hexagon and the 12-connected truncated tetrahedron, giving the mgc topology. In addition, the trinodal nets with a minimal number of links (minimal edge-transitive), kex, cez, and kez, should be mentioned. ${ }^{20-22}$

The experimental basis of our work is based on the distinctly hexagon-shaped hexatopic building block 1,2,3,4,5,6-hexakis(4carboxyphenyl)benzene, $\mathrm{cpb}^{6-}$ (Chart 1 ), with $\mathrm{Bi}(\mathrm{III}), \mathrm{Cu}(\mathrm{II})$, $\mathrm{Fe}(\mathrm{II}), \mathrm{Co}(\mathrm{II})$, and $\mathrm{Zn}(\mathrm{II}) . \mathrm{H}_{6} \mathrm{cpb}$ is one of a few such flat and rigid hexagon-shaped building blocks used in MOF chemistry, and only one material with a well-characterized 3D hexagonbased network topology has been reported earlier, $\left[\mathrm{Cu}_{3}(\mathrm{cpb})\right.$ $\left.(\mathrm{dmf})_{0.5}\right] \cdot 6 \mathrm{H}_{2} \mathrm{O}$ (MOF-890), with the net symbol htp, the first compound combining hexagons and triangular prisms (thus a 2-nodal 6-connected net). ${ }^{23}$ Apart from the structural studies, we will demonstrate the use of time of flight secondary ion mass spectrometry (ToF-SIMS) to elucidate the interior contents of MOFs.

The theoretical part is a direct offspring of our structural analysis and related to our recent work on metal-oxalate topologies. ${ }^{24}$ We were, among other things, intrigued by the absence in the literature of a $3 \mathrm{D}$ net combining hexagons and
Chart 1. 1,2,3,4,5,6-Hexakis(4-carboxyphenyl)benzene, $\mathrm{cpb}^{6-}$, with the Different Connection Modes Encountered in This Work ${ }^{a}$<smiles>[M]OC(=O)c1ccc(-c2c(-c3ccc(C(=O)O)cc3)c(-c3ccc(C(=O)O[M])cc3)c(-c3ccc(C(=O)O[M])cc3)c(-c3ccc(C(=O)O[M])cc3)c2-c2ccc(C(=O)O[M])cc2)cc1</smiles>

${ }^{a}$ Clockwise from left: the hydrogen bond synthon; chelation; monodentate coordination; the connection to a paddle-wheel metal secondary building unit (SBU). The conformational chirality of the $\mathrm{cpb}$ unit is emphasized by bold bonds.

triangles, which led us to model building and the concept of foldable nets.

\section{RESULTS AND DISCUSSION}

Reticular Chemistry of CTH-6 to CTH-13. CTH-6 forms a 3- and 6-connected net by $\mathrm{Bi}$ (III) binding three $\mathrm{cpb}^{6-}$ ligands by chelation (mode $\mathrm{B}, \mathrm{Chart} 1$ ). This gives the well-known $3 \mathrm{D}$ rutile, or rtl, topology, Figure 2, but unlike the common,

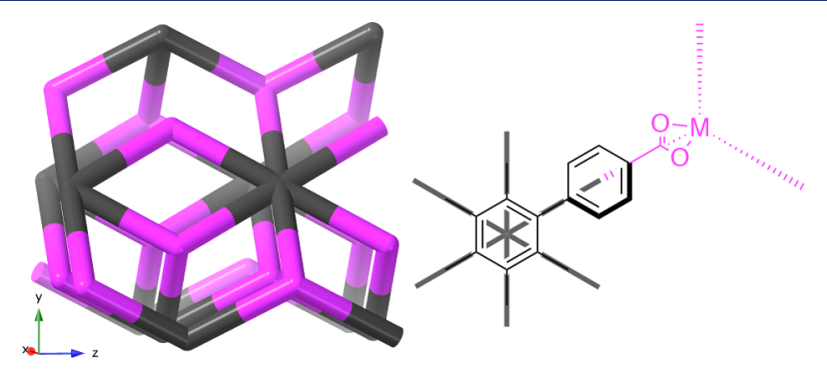

Figure 2. CTH-6 $\left[\mathrm{Bi}_{2}(\mathrm{cpb})(\mathrm{HOAc})_{2}(\mathrm{dmf})_{4}\right]$ with $\mathrm{Bi}$ as 3-connected purple nodes and $\mathrm{cpb}^{6-}$ centroids as 6-connected nodes in black. This gives a hexagon and trigonal pyramid version (embedding) of the otherwise octahedron and triangle-based rtl-net.

highest symmetry version of this net based on triangles and octahedra, this variety (or embedding) is instead constructed from hexagons and trigonal pyramids.

CTH-8 and CTH-9 are isostructural, and Fe(II) (CTH-8) and $\mathrm{Co}$ (II) (CTH-9) bind to $\mathrm{cpb}^{6-}$ using mode D in Chart 1 to form binuclear trigonal paddle-wheels further connected axially by acetate ions to give a 5- and 6-connected net. This forms the yav-net, combining hexagons and trigonal bipyramids. The yav-net has earlier been reported for $\mathrm{H}_{2} \mathrm{cpb}^{4-}$ in MOF-889, where the axial links are formed by hydrogen bonding. ${ }^{23}$

Such a yav-net by hydrogen bonding is also found in CTH13, with a 3- and 6-connected 2D kagome dual net, or kgd-net, formed by tetrahedral $\mathrm{Zn}(\mathrm{II})$ ions binding three $\mathrm{cpb}^{6-}$ in mode C (Chart 1), with additional coordinated water hydrogen bonding to the $\mathrm{Zn}$ (II) secondary building unit (SBU) in the next layer, making $\mathrm{Zn}$ into 5-connected nodes; see Figure 3. 

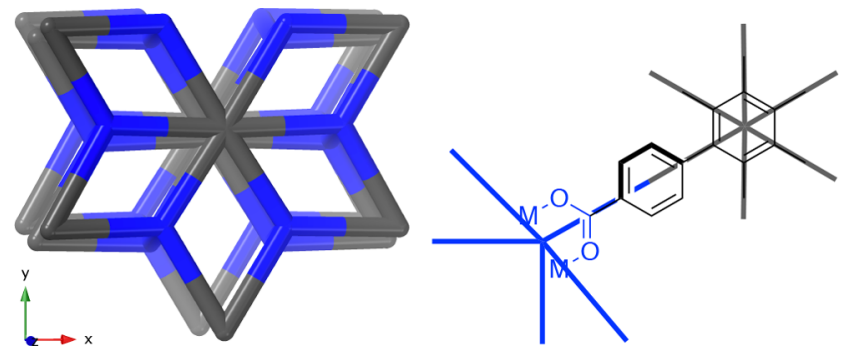

Figure 3. yav net in CTH-8 and -9 $\left[\mathrm{M}_{4}(\mathrm{cpb})(\text { acetato })_{2}(\mathrm{dmf})_{4}\right]$ with $\mathrm{Fe}(\mathrm{II})$ or $\mathrm{Co}$ (II) as 3-connected blue nodes and $\mathrm{cpb}^{6-}$ centroids as 6connected nodes in black. Acetate ions form the axial blue connections. A similar, but mixed coordination and hydrogen-bonded, yav net is found in CTH-13 $2\left(\mathrm{H}_{2} \mathrm{NMe}_{2}\right)\left[\mathrm{Zn}_{2}(\mathrm{cpb})\left(\mathrm{H}_{2} \mathrm{O}\right)_{2}\right] \cdot 2 \mathrm{dmf}$.

Another mixed coordination and hydrogen-bonded net is found in CTH-12 with $\mathrm{H}_{2} \mathrm{Cpb}^{4-}$, where a paddle-wheel, mode $\mathrm{D}$, is combined with mode $\mathrm{A}$ to the square lattice $2 \mathrm{D}$ sql-net.

Finally, CTH-7, CTH-10, Zn-MOF-888, and CTH-11 all adopt the 3- and 6-connected 2D kgd-net frequently seen with hexagonal and triangular nodes having chiral tris-carboxylate coordination entities as 3-connected nodes. These compounds differ in the metal ions, $\mathrm{Cu}(\mathrm{II}), \mathrm{Fe}(\mathrm{II})$, and $\mathrm{Zn}$ (II), but also in the cations need for charge balance and the spacing and relative orientation of the kgd-nets.

As octahedral coordination is very common for the metal ions, it is perhaps not surprising that out of the 13 MOFs prepared to date using the cpb ligand, six adopt the kgd-net with tris-bis-chelating metal SBUs. Also, for the one benzene ring extended version of $\mathrm{H}_{6} \mathrm{cpb}$, hexakis(4-(4-carboxylphenyl)phenyl)benzene, $\left.\mathrm{H}_{6} \mathrm{cppb}\right)$, this is the most common net, with two out of four structures (CEFNIN she, FEKEK kgd, FAKKIO kgd, IXETEM hxg).

With $\mathrm{M}^{2+}$ ions these kgd-nets need cations to balance the charged layers. As is clear from Figure 4, each three-connected

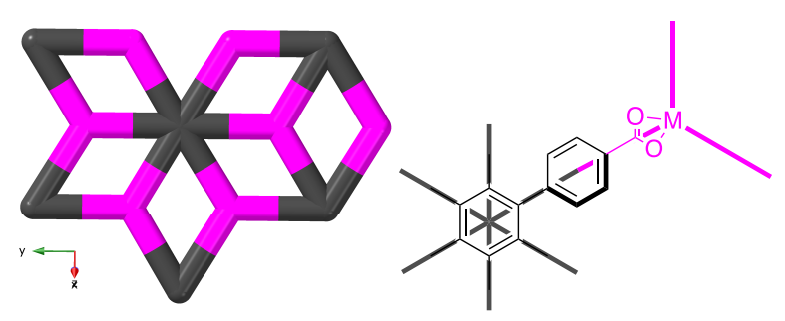

Figure 4. 2D kgd net in CTH-7, CTH-10, Zn-MOF-888, and CTH11, 2 (cation) $\left[\mathrm{M}(\mathrm{II})_{2}(\mathrm{cpb})\right] \cdot$ solvent.

vertex has three voids, and each void is shared by two metal ions, with the ratio of void to metal of $3 / 2$. In the structures reported here, different cations fill these voids and cause a variety of sheet packings of the $2 \mathrm{D}$ nets discussed further on in the article.

Derivation of the laf-net. The question then occurred to us, what happens if the cations are too big for these voids? For metal-tris-oxalates, a $3 \mathrm{D}$ network is assured when the propagation vectors are turned out of the plane by having the same chirality on all the metal centers, giving the srs-net, the most symmetric way of assembling trigonal vertices. ${ }^{24,25}$ Can something similar happen with the kgd-nets? In our kgd cases, all coordination entities around the hexagon have the same chirality. What if this changes? No net like this, combining perfectly planar equilateral triangles with planar hexagons, has been described in the literature, but physical model building showed this was indeed possible; see Figure 5.

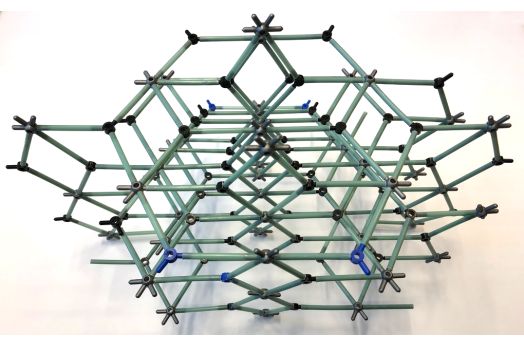

Figure 5. Orbit molecular modeling of the laf-net.

The unit cell, space group, and coordinates of the vertices in the model were determined, and Systre ${ }^{17}$ was used to calculate the most symmetric embedding of the network topology laf; see Figure 6. The net has edge transitivity two, that is two symmetry-independent links, but with equal lengths, and the point symbols of the new net are $4.8^{2}$ and $4^{2} \cdot 8^{11} \cdot 10^{2}$.

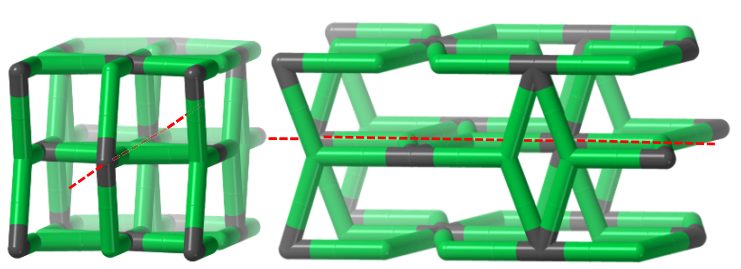

Figure 6. Two views of the new laf-net, the only net combining perfect hexagons and perfect equilateral triangles. Folding is possible along the dashed red line coinciding with the direction of the tetragonal $z$-axis. Note there is no unbroken axis going through the network.

Though not described before, the laf-net can be found in the ToposPro $^{26}$ TTD collection as 'alb-3,6-P42/ $\mathrm{mnm}^{2}$ ' (related to the 6- and 12-connected alb-net), and the search routine yields a few examples. Two compounds stand out as very clear examples (although not discussed as such in the literature): lithium oxalate LIOXAT ( $\mathrm{Li} 3-\mathrm{c}$, oxalate 6-c), and the hydrogen-bonded bis(guanidinium) 3,6-dinitropyrazolo[4,3c] pyrazole-1,4-diide, HUCSOP (guanidinium 3-c, pyrazolopyrazole 6-c).

The laf-net has large rectangular channels running in two directions, and we speculate that larger cations, not fitting into the space in the kgd-nets, might template this network just as some larger cations induce the srs and other 3D-nets in the tris-oxalate-based systems. ${ }^{24,25,27}$

The Concept of Foldable Nets. Inspecting the physical model in Figure 5, we noted that this net can be "folded" along the tetragonal axis while the individual hexagonal and trigonal geometries stay exactly the same; see Figure 7 . This property is directly related to the topology of the net and may also translate into real physical properties of a material. It thus merits a bit of discussion, and a MOF based on this topology may potentially be a "breathing" MOF, like MIL-53. ${ }^{28}$

Flexibility in MOFs may have different origins, for example the rather fluid coordination sphere around Bi being one such factor. $^{29,30}$ Some detailed accounts of different systems have emerged, ${ }^{31-35}$ where changes in geometry and ligand conformations are discussed, but little attention seems to have been given to the influence of the topology as such. Férey 


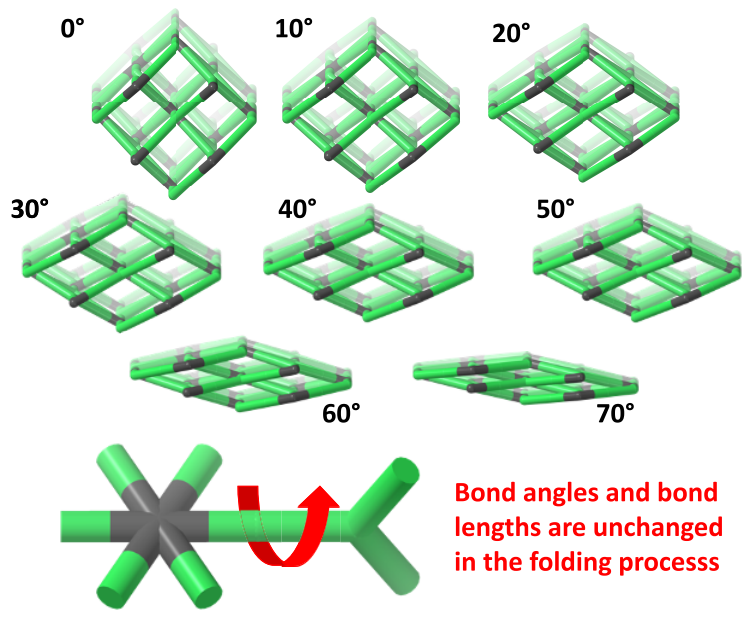

Figure 7. Folding of the laf-net is accomplished without changing the geometry of the individual vertices, only by rotation around the trigonal-hexagonal axis. Thus, the bond angles and bond lengths of the individual hexagonal and trigonal centers stay the same.

and Serre invoke "the existence of only even cycles", 31 and Wei et al. ${ }^{34}$ note that the specific 9- and 3-connected $\mathbf{x m z}$ topology "has a special restriction to the framework breathing mode" but without drawing any general conclusions.

We would like to propose the term foldable network topologies (to make the distinction from the more general case of breathing or flexible MOFs) for nets such as laf and offer the following tentative definition (assuming vertices and links are infinitely small): Foldable network topologies are topologies that can fold into a flat projection by free rotation between vertices while the angles and edge lengths around each vertex is unchanged.

Two conditions appear to be needed for this: First, the vertices must be flat, rather than polyhedral (hexagons, squares, triangles rather than tetrahedra). Flat vertices are, however, not enough. For example, the square-based nbonet and cds-net behave quite differently. The nbo-net is rigid (easily verifiable on a physical model), while the cds is foldable.

So, we need to look at the smallest rings in the nets along potential folding axes. The laf-net is folded around an axis passing through 8-rings (with $60^{\circ}$ and $120^{\circ}$ angles) with two sides parallel to the folding axis, and these 8 -rings can be folded flat. The cds-net has 6-rings that are already flat, while the 6rings in the nbo-net are not flat and cannot be folded flat without compromising the coordination geometry around some vertices. The second condition thus appears to be that the folding axis must pass through the smallest rings that are, or can be, folded flat around the folding axis. Two sides of these rings then need to be parallel.

These are not properties that can be directly obtained from the RCSR database; however inspecting a number of candidate nets reveals a few examples. Thus, we have identified foldable topologies with all three basic flat polygons, the triangle, the square, and the hexagon, and their combinations, except for the hexagon on its own; see Table 1.

In terms of space groups we see that all these foldables are either tetragonal (all angles $90^{\circ}$, foldable along the unique $c$ axis perpendicular to the $a$ - $=b$-axes) or orthorhombic (all angles $90^{\circ}$, foldable along the unique $c$-axis perpendicular to
Table 1. Examples of Foldable Topologies

\begin{tabular}{|c|c|c|c|c|}
\hline net & vertices $^{a}$ & space gr. & point symbol & links \\
\hline ths & tri & $I 4_{1} / a m d$ & $10^{3}$ & 2 \\
\hline \multirow[t]{2}{*}{ clh } & tri & $P 4_{2} / m m c$ & $6^{2} .12$ & 3 \\
\hline & tri & & $6.12^{2}$ & \\
\hline \multirow[t]{2}{*}{ cds-a } & tri & $P 4_{2} / m m c$ & $4.14^{2}$ & 3 \\
\hline & tri & & $4.14^{2}$ & \\
\hline cds & sq & $\mathrm{P} 4_{2} / \mathrm{mmc}$ & $6^{6}$ & 2 \\
\hline cdl & sq & $P 4_{2} / m m c$ & $4.8^{5}$ & 3 \\
\hline \multirow[t]{2}{*}{$\operatorname{cdz}$} & $\mathrm{sq}$ & Pmmm & $6^{2} .8^{4}$ & 4 \\
\hline & sq & & $4^{2} \cdot 6^{2} \cdot 8^{2}$ & \\
\hline \multirow[t]{3}{*}{ sqc163 ${ }^{b}$} & tri & Pmmm & $6.8^{2}$ & 4 \\
\hline & tri & & $6^{2} .8$ & \\
\hline & $\mathrm{sq}$ & & $8.10^{4} .12$ & \\
\hline \multirow[t]{2}{*}{ tff } & tri & $\mathrm{Cmmm}$ & $8^{3}$ & 3 \\
\hline & $\mathrm{sq}$ & & $8^{6}$ & \\
\hline \multirow[t]{2}{*}{$\mathrm{tfk}$} & tri & $P 4_{2} / m m c$ & $4.12^{2}$ & 2 \\
\hline & sq & & $4^{2} .12^{4}$ & \\
\hline \multirow[t]{2}{*}{ laf } & tri & $P 4_{2 / m n m}$ & $4.8^{2}$ & 2 \\
\hline & hex & & $4^{2} .8^{13}$ & \\
\hline \multirow[t]{2}{*}{ jem } & sq & $\mathrm{Cmmm}$ & $4.6^{4} .8$ & 3 \\
\hline & hex & & $6^{8} .6^{7}$ & \\
\hline
\end{tabular}

${ }^{a}$ hex $=$ hexagons, tri $=$ triangles, $\mathrm{sq}=$ square. ${ }^{b}$ In the EPINET database.

the $a$ - $\neq b$-axes $)$. As they fold, these space groups will change to the monoclinic system.

We see a few space groups being predominant in Table 1, but this does not mean that all nets in these space groups are foldable. A requirement, however, is a $C_{2}$-axis coinciding with the folding axis. A few of these nets are illustrated in Figure 8.

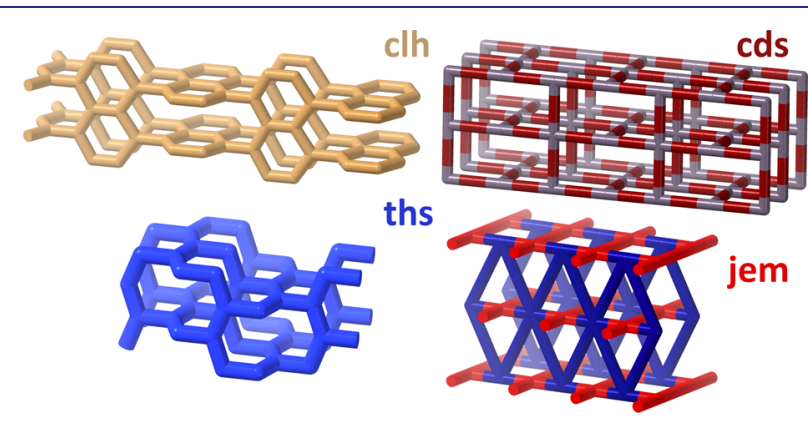

Figure 8. Four of the foldable nets from Table 1, illustrating 3connected (clh and ths), 4-connected (cds), and 4- and 6-connected (jem) nets.

The MIL-53 systems and the similar 4,4'-(1,4-phenylene)bis(pyrazolato) MOFs from the Long group ${ }^{36}$ are probably the best known breathing MOFs. They are so-called rod-MOFs, having infinite metal SBUs running in one direction. Formally we would assign them the sra topology, ${ }^{37}$ built from ladders of tetrahedra, and thus not foldable. However, as the ligand SBUs all attach to the same points of the rod, an alternative simplified description would be the cds-net. ${ }^{38}$ Not surprisingly perhaps the cds-net exactly corresponds to the wine-rack analogy often invoked to explain the breathing phenomena in these materials.

An important observation from Table 1 might be that not all these nets are compatible with rod-MOFs (i.e., ths, clh, laf), and thus breathing MOFs may be constructed by other metal SBUs than infinite rods. 
Detailed Structure Analysis of CTH-6 to CTH-13. Crystal data, experimental, and refinement parameters are given in Table $S 1$ and Table $S 2$ in the Supporting Information.

CTH-6, $\left[B i_{2}(c p b)(H O A C)_{2}(d m f)_{4}\right]$. The structure analysis indicates that in $\mathrm{CTH}-6$ each $\mathrm{Bi}(\mathrm{III})$ center is coordinated to nine oxygen atoms: six from a carboxylate group from three cpb linkers, two dimethylformamide (dmf) molecules, and an acetic acid molecule. The last two have $\mathrm{Bi}-\mathrm{O}$ bond lengths of 3.056(7) and 2.850(8) Å, respectively, significantly longer than the $\mathrm{Bi}-\mathrm{O}$ carboxylate bonds to the cpb linker that range from 2.208 to $2.218 \AA$. The $\mathrm{dmf}$ with the longer $\mathrm{Bi}-\mathrm{O}$ bond also hydrogen bonds to the acetic acid. See Figure 9. With all atoms counted the void volume calculated from the crystal structure is $34 \%$ with spherical cavities of diameter $2.4 \AA$.

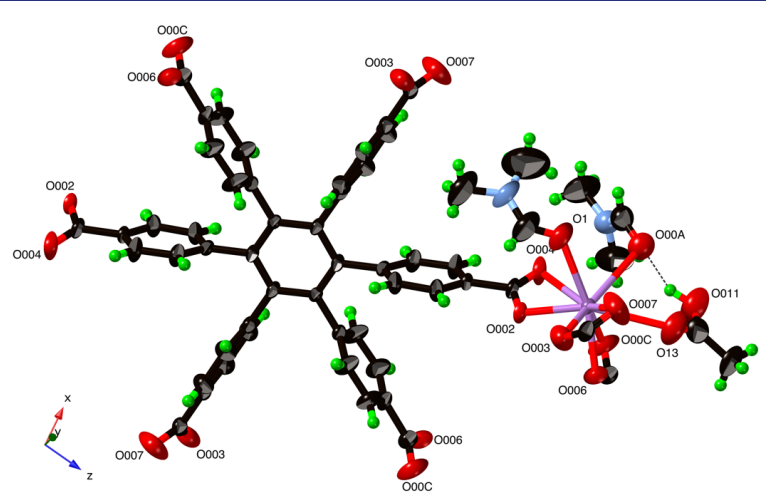

Figure 9. CTH-6 $\left[\mathrm{Bi}_{2}(\mathrm{cpb})(\mathrm{HOAc})_{2}(\mathrm{dmf})_{4}\right] \mathrm{Bi}-\mathrm{O}$ bonds are on the order of $2.22 \AA$ to $3.06 \AA$. Ellipsoids are drawn at $50 \%$ probability. The rtl-net in the structure is illustrated in Figure 2.

CTH-7, 2(Hdma) $\left[\mathrm{Cu}_{2}(\mathrm{cpb})\right]$. The asymmetric unit consists of two $\mathrm{Cu}$ (II) ions, half a cpb linker, and one dimethylammonium cation $\left(\mathrm{Hdma}^{+}\right)$. The framework comprises mononuclear $\mathrm{Cu}(\mathrm{II})$ octahedral entities with three points of extension (Figure 10) because of the coordinated $\mathrm{cpb}$ linker. The two $\mathrm{Cu}$ (II) sites display Jahn-Teller distortions of opposite kinds. The Cul entity that does not take part in the hydrogen bonding displays four shorter (1.95-2.03 $\AA$ ) and two longer

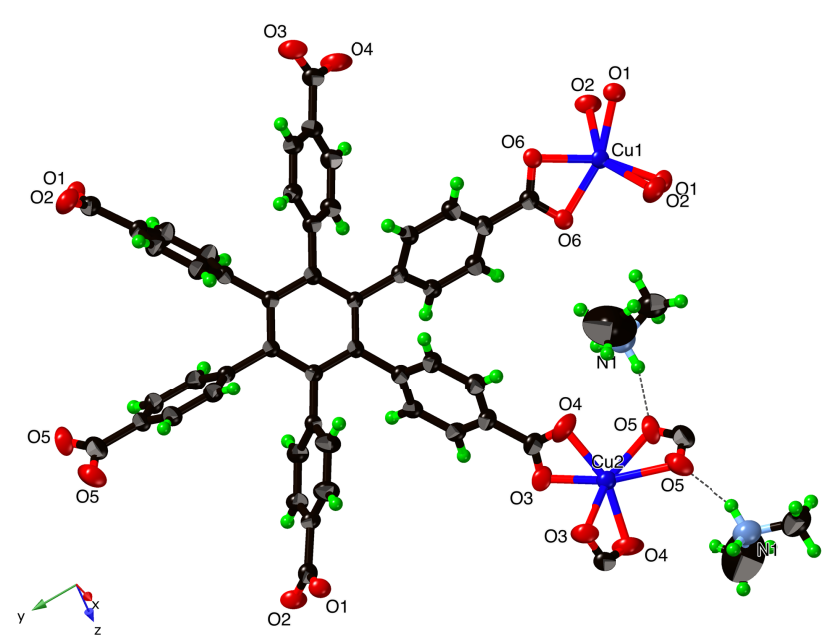

Figure 10. CTH-7, 2(Hdma) $\left[\mathrm{Cu}_{2}(\mathrm{cpb})\right]$. The two $\mathrm{Cu}$ sites display opposite Jahn-Teller distortions, and only $\mathrm{Cu} 2$ has hydrogen-bonded $\mathrm{Hdma}^{+}$ions. Ellipsoids are drawn at $50 \%$ probability. The kgd-net in the structure is illustrated in Figure 4.
(2.51 $\AA$ ) $\mathrm{Cu}-\mathrm{O}$ bonds. The $\mathrm{Cu} 2$ site (Figure 10) has two shorter $(1.99 \AA)$ and four longer $(2.21-2.22 \AA) \mathrm{Cu}-\mathrm{O}$ bonds.

Due to high synthesis temperature, the $\mathrm{dmf}$ decomposed to dimethylamine (dma), which is subsequently protonated and thereby compensates for the common copper oxidation state of $2+$. There is hydrogen bonding between one hydrogen (H1B) of the $\mathrm{Hdma}^{+}$cation and the oxygen atom (O5) of the cpb linker forming a $\mathrm{NH} \cdots \mathrm{O}$ interaction. This occurs for the $\mathrm{Cu} 2$ site and is possibly related to the Jahn-Teller distortion observed. The CTH-7 structure is further supported by weak $\mathrm{CH} \cdots \mathrm{O}$ and $\mathrm{CH} \cdots \pi$ interactions. See Figure 10.

Analysis of the void volume in the crystal structure indicates $40 \%$ empty space in the unit cell and connected cavities with radii of 2.6 and $1.0 \AA$ respectively, potentially large enough to harbor a dmf molecule. One out of three rhombic-shaped pockets in Figure4 is empty and corresponds to these calculated voids.

CTH-8 $\left[\mathrm{Fe}_{4}(\mathrm{cpb})(\text { acetato })_{2}(\mathrm{dmf})_{4}\right]$. The asymmetric unit contains four $\mathrm{Fe}$ (II) centers, two half $\mathrm{cpb}$ molecules, four $\mathrm{dmf}$ molecules, and two acetate anions. There are four crystallographically independent $\mathrm{Fe}$ atoms in the structure. Fel is connected to three monodentate carboxylates, two dmf, and one acetate anion. $\mathrm{Fe} 2$ is coordinated to two monodentate carboxylates, one bidentate carboxylate, and one acetate anion. The third Fe3 is linked to two monodentate carboxylates, one bidentate carboxylate, one $\mathrm{dmf}$, and one acetate anion, and finally the fourth, Fe4, connects with three monodentate carboxylates, one $\mathrm{dmf}$ and one acetate anion. The acetate anions in CTH-8 bridge all the $\mathrm{Fe}$ atoms found in the framework; see Figure 11. The hexagonal spatial arrangement of the cpb linker and the trigonal bipyramid geometry results in the $3 \mathrm{D}$ yav topology (Figure 3$).{ }^{18}$ Void volume was calculated as $36 \%$ with spherical cavities with diameters of 3.4 and $3.2 \AA$.

CTH-9 $\left[\mathrm{CO}_{4}(\mathrm{cpb})(\text { acetato })_{2}(\mathrm{dmf})_{4}\right]$. CTH-9 $\left[\mathrm{Co}_{4}(\mathrm{cpb})\right.$ (acetato $\left.)_{2}(\mathrm{dmf})_{4}\right]$ is isostructural with CTH-8, as the unit cell parameters are similar, the space group is identical, and the asymmetric unit content is the same, except $\mathrm{Fe}$ is replaced by Co. Figure 11 thus illustrates also CTH-9.

CTH-10 ( $\left.\mathrm{HNEt}_{3}\right)_{2}\left[\mathrm{Fe}_{2}(\mathrm{cpb})\right]$. CTH-10 $\left(\mathrm{HNEt}_{3}\right)_{2}\left[\mathrm{Fe}_{2}(\mathrm{cpb})\right]$ crystallizes in the monoclinic chiro-descriptive space group $P 2_{1}$ with $Z=2$. In the asymmetric unit, there are two $\mathrm{cpb}^{6-}$ ligands, four $\mathrm{Fe}$ atoms, and four protonated triethylamine $\left(\mathrm{Htea}^{+}\right.$) molecules. These four protonated $\mathrm{Htea}^{+}$molecules are each hydrogen-bonded to the neighboring carboxylate group of the $\mathrm{cpb}^{6-}$, forming $\mathrm{N}-\mathrm{H} \cdots \mathrm{O}$ interactions; see Figure 12 . The CTH-10 structure is further stabilized by $\mathrm{C}-\mathrm{H} \cdots \mathrm{O}$ and $\mathrm{C}-$ $\mathrm{H} \cdots \pi$ interactions.

From a supramolecular point of view, there are three distinct iron coordination entities: $\mathrm{Fe} 01$ has two hydrogen-bonded $\mathrm{Htea}^{+}$ions ( $\mathrm{N} \cdots \mathrm{O} 3.08-3.23 \AA$ ), $\mathrm{Fe} 03$ and $\mathrm{Fe} 04$ have one hydrogen-bonded $\mathrm{Htea}^{+}$( $\mathrm{N} \cdots \mathrm{O}$ 2.73-2.85 $\AA$ ), while Fe02 has no hydrogen-bonded $\mathrm{Htea}^{+}$attached at all. (Note that in CTH-7 we saw two different $\mathrm{Cu}$ sites.) This also explains the chirality of the structure, because as the chirality changes between each layer, the supramolecular coordination entities also change, meaning that entities with one or zero $\mathrm{Htea}^{+}$ions attached always have one chirality, and the ones with a single $\mathrm{Htea}^{+}$ion hydrogen-bonded always have the opposite chirality. (The Flack parameter is close to 0.5 , so the crystal is racemic; the structure however is chiral.)

The packing is very different from that in CTH-7, now forming four distinctive layers in the unit cell, as the triethylammonium ions do not fit in a single kgd-void but 


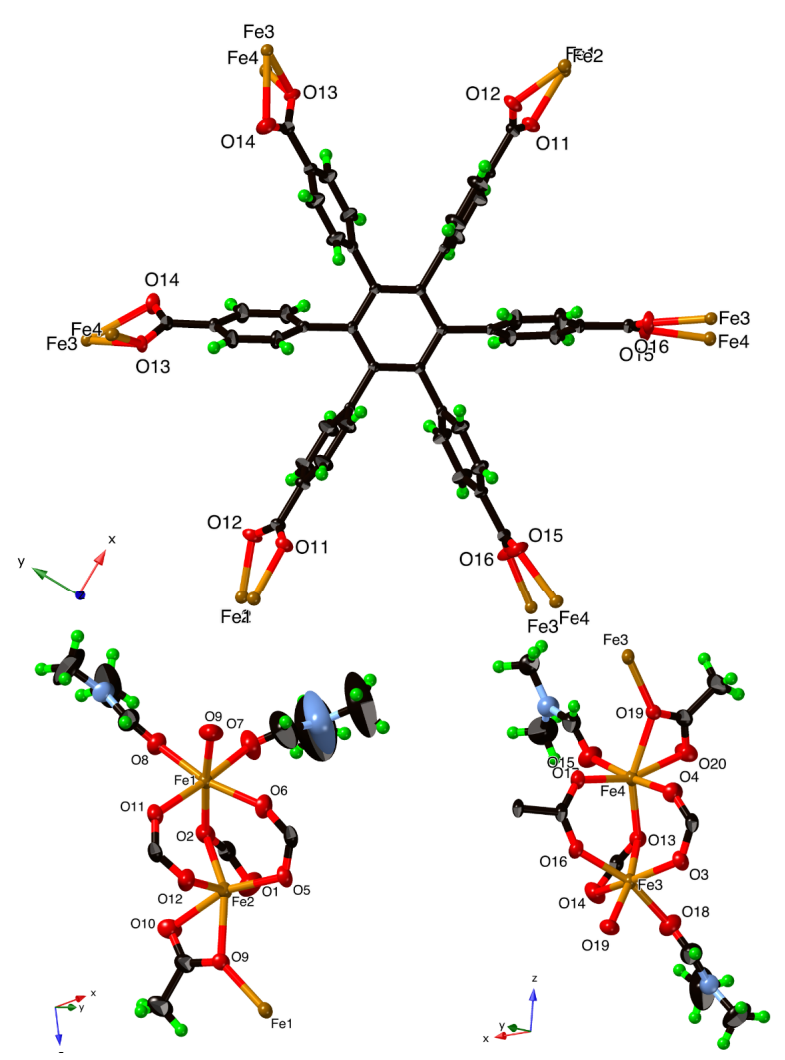

Figure 11. Three different views of CTH-8 $\left[\mathrm{Fe}_{4}(\mathrm{cpb})\right.$ (acetato $\left.)_{2}(\mathrm{dmf})_{4}\right]$ showing the different parts of the structure (CTH-9 with Co is isostructural). Ellipsoids are drawn at 50\% probability. The yav net in these structures is illustrated in Figure 3.

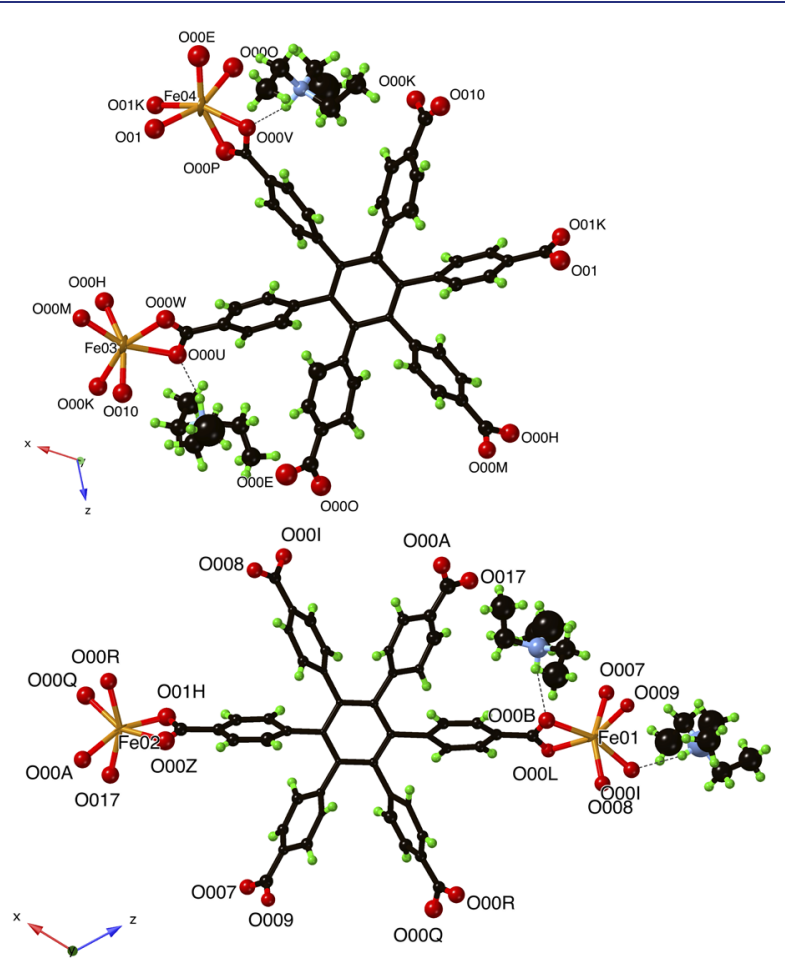

Figure 12. Molecular units form the two symmetry-independent kgdnets in CTH-10, $\left(\mathrm{HNEt}_{3}\right)_{2}\left[\mathrm{Fe}_{2}(\mathrm{cpb})\right]$, showing the different parts of the structure. need to share with an empty void in a neighboring sheet. Figure 13 illustrates this. Void volume was calculated as 35\%, with the largest cavity with a diameter of $3 \AA$.

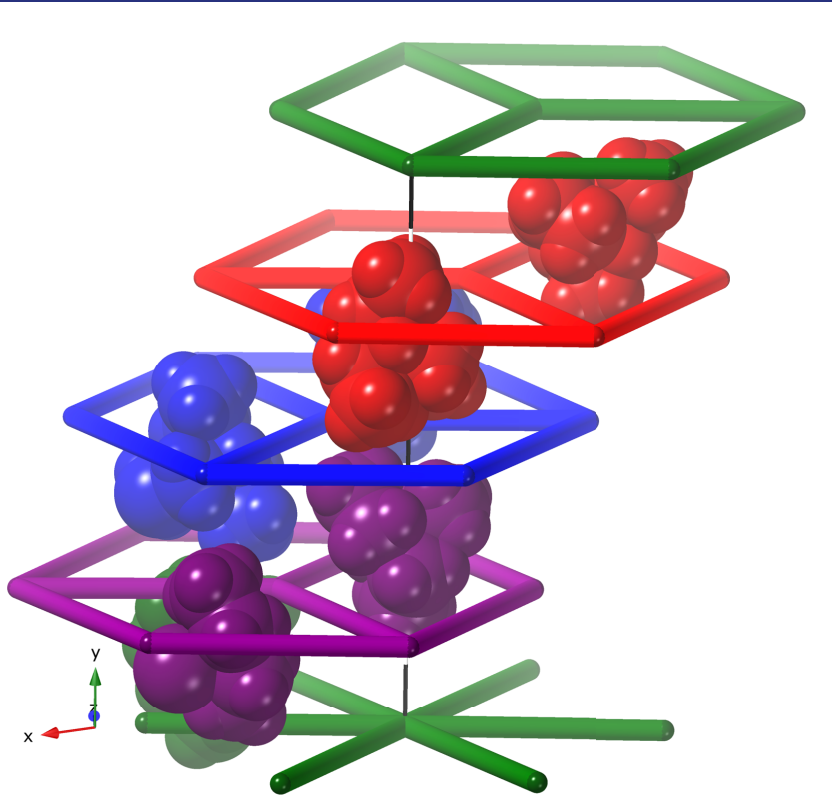

Figure 13. Network packing in the CTH-10. The unit cell comprises four different kgd-layers depicted in green, violet, blue, and red, two of them symmetry independent. The triethylammonium ions attached by hydrogen bonds to each layer are presented in the same color. The axis defining the compartments capped by cpb ligands is indicated with a dashed white and black line. Note how the empty compartments in each layer have a counterion from another layer penetrating it.

$\mathrm{Zn}-\mathrm{MOF}-888$ and $\mathrm{CTH}-11,2\left(\mathrm{H}_{2} \mathrm{NMe}_{2}\right)\left[\mathrm{Zn}_{2}(\mathrm{cpb})\right] \cdot 1.5 \mathrm{dmac}$, form two polymorphs that grew concomitantly. They were both colorless and had the same morphology. The two polymorphs could not be separated under a microscope for thermal analysis (TGA) because their crystals grew on top of each other like twins. Single-crystal X-ray diffraction data of either of the two polymorphs were not possible due to the microscale particle sizes of $2 \mu \mathrm{m}$ for Zn-MOF-888 and $1 \mu \mathrm{m}$ for CTH-11 acquired from transmission electron microscopy (Figure S2, SI). Instead, 3D electron diffraction (3D ED) was employed by crushing the needle-shaped crystals, permitting structure determination of the two polymorphs. ${ }^{39}$

Both polymorphs crystallize in the monoclinic system space group $\mathrm{C} 2 / \mathrm{c}$ with $\mathrm{Z}=2$. Hydrogen atoms were omitted in the polymorphs' data refinement. The asymmetric unit of $\mathbf{Z n}$ MOF-888 contains two $\mathrm{Zn}$ atoms, a half $\mathrm{cpb}$ linker, and the presence of some charge-balancing species in the framework cavities as for CTH-7. On the other hand, the asymmetric unit of CTH-11 consists of one $\mathrm{Zn}$ atom, half a cpb molecule, and some charge-balancing electron density located in the structure cavities that could not be adequately modeled. Packing diagrams for the two polymorphs viewed along [001] are illustrated in Figures S3 and S4. They resemble the CTH-7 structure from the framework and kgd topology point of view but are not isostructural. Zn-MOF-888, however, appears to be isostructural with MOF-888 (CSD code AZAVII), [ $\left.\mathrm{Ni}_{2}(\mathrm{cpb})\right]$. $4.1 \mathrm{H}_{2} \mathrm{O},{ }^{23}$ which may cast some doubt on the inferred oxidation state $\mathrm{Ni}(\mathrm{III})$ in the latter compound, as no extraframework molecules could be identified or modeled in that 
case either. The TGA and elemental analysis of Zn-MOF-888 and CTH-11 indicate the presence of the counterion $\mathrm{H}_{2} \mathrm{NMe}_{2}$ and dmac in the cavities of these structures.

The single-crystal structure of $\mathrm{CTH}-12,\left[\mathrm{Cu}_{2}(\mathrm{cpb})\right.$ (acetato $\left.)_{2}(\mathrm{dmf})_{2}\right] \cdot 2 d m f$, comprises one $\mathrm{Cu}$ (II) atom, half a cpb molecule, two dmf, and one acetate anion in its asymmetric unit. The $\mathrm{Cu}(\mathrm{II})$ center is connected to one $\mathrm{cpb}$, one $\mathrm{dmf}$ (which is disordered with site occupancy factors of 0.533 and 0.467 , respectively), and one acetate ion, forming a paddle-wheel with $\mathrm{dmf}$ in the axial positions; see Figure 14.

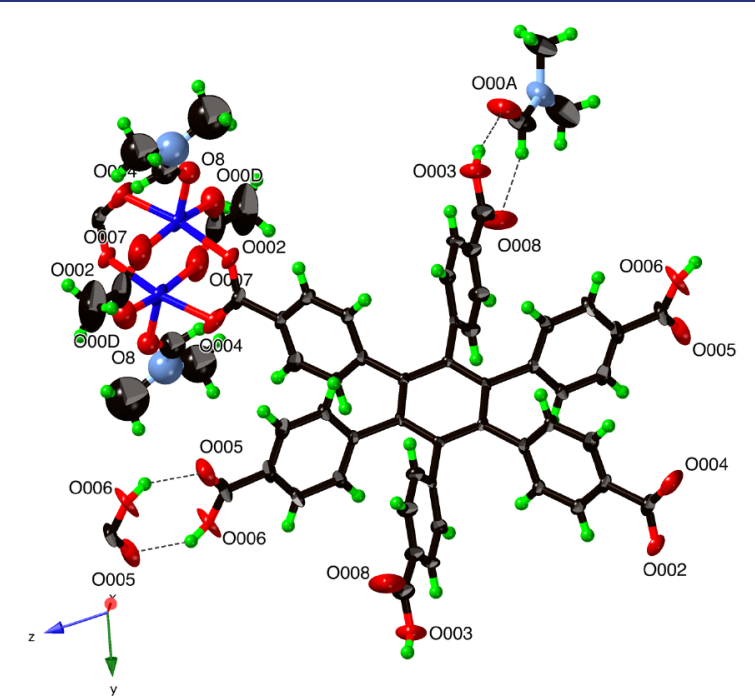

Figure 14. CTH-12 with ellipsoids drawn at 50\% probability. The resulting sql-net in the structure is illustrated in Figure 15.

Only two of the six carboxylic acid moieties of the cpb linker are fully deprotonated; the other carboxylic acids are involved in hydrogen bonding with either themselves, forming a dimer resulting in $\mathrm{R}_{2}^{2}(8)$ rings using graph-set notation, ${ }^{40}$ or with the uncoordinated $\mathrm{dmf}$ molecule, forming the homosynthon $\mathrm{R}_{2}^{2}(8)$ through a weak $\mathrm{CH} \cdots \mathrm{O}$ interaction. The solventaccessible volume calculated from the crystal structure data is $36 \%$, and the largest calculated spherical void has a diameter of $3.6 \AA$ A.

We note that among the 373 structures found in the CSD that contain a paddle-wheel motif with at least two acetates bonded to $\mathrm{Cu}(\mathrm{II})$, there are only eight compounds that are not homoleptic in this core structure; the rest, $98 \%$, all have four acetate ions forming the paddles on the wheel. Moreover, CTH-12 appears to be the only example of the paddle-wheel forming a linear connecting SBU in a coordination polymer or MOF. On the other hand, there are plenty of examples where the paddle-wheel acts as a linear connector by additional axial ligands.

CTH-13, yav-2 $\left(\mathrm{H}_{2} \mathrm{NMe}_{2}\right)\left[\mathrm{Zn}_{2}(\mathrm{cpb})\left(\mathrm{H}_{2} \mathrm{O}\right)_{2}\right] \cdot 2 d m f$. CTH-13, yav- $2\left(\mathrm{H}_{2} \mathrm{NMe}_{2}\right)\left[\mathrm{Zn}_{2}(\mathrm{cpb})\left(\mathrm{H}_{2} \mathrm{O}\right)_{2}\right] \cdot 2 \mathrm{dmf}$, crystallizes in the monoclinic system space group $\mathrm{C} 2 / \mathrm{c}$ and differs from the two other $\mathrm{Zn}-\mathrm{MOF}$ in this study in that the $\mathrm{Zn}(\mathrm{II})$ ions have a distinct tetrahedral coordination instead of octahedral, and the fourth coordination site is occupied by a coordinated water molecule. This water ligand holds the kgd coordination network sheets together by strong hydrogen bonds, $\mathrm{O}-\mathrm{H} \cdots$ $\mathrm{O}=\mathrm{C} 2.655 \AA, 1.810 \AA, 175^{\circ}$ forming $\mathrm{R}_{1}^{1}(10)$ rings using graph-set notation. The third carbonyl oxygen is hydrogen

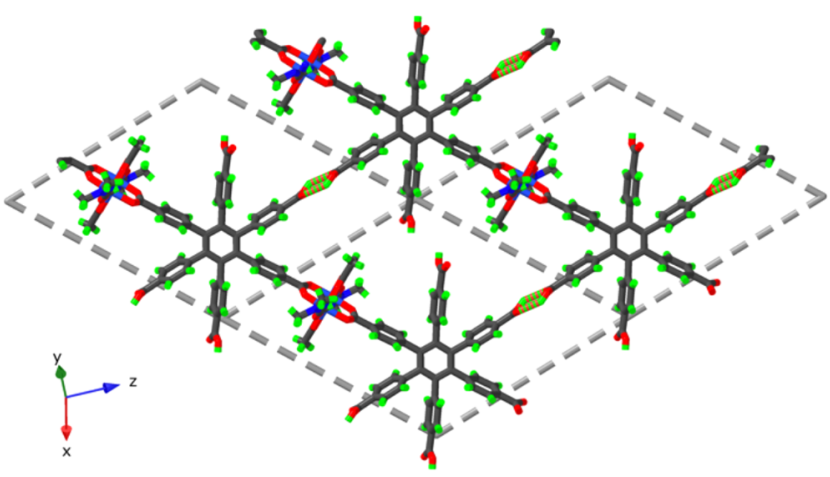

Figure 15. CTH-12 with the sql-net with the $\mathrm{dmf}$ and unresolved solvent molecules in the hidden voids. Also shown in gray dashed lines is the position of the sql-net in the next layer.

bonding to the $\mathrm{Hdma}^{+}$cation $\mathrm{N}-\mathrm{H} \cdots \mathrm{O}=\mathrm{C} 2.61 \AA$, $1.85 \AA$, $142^{\circ}$. See Figure 16 .

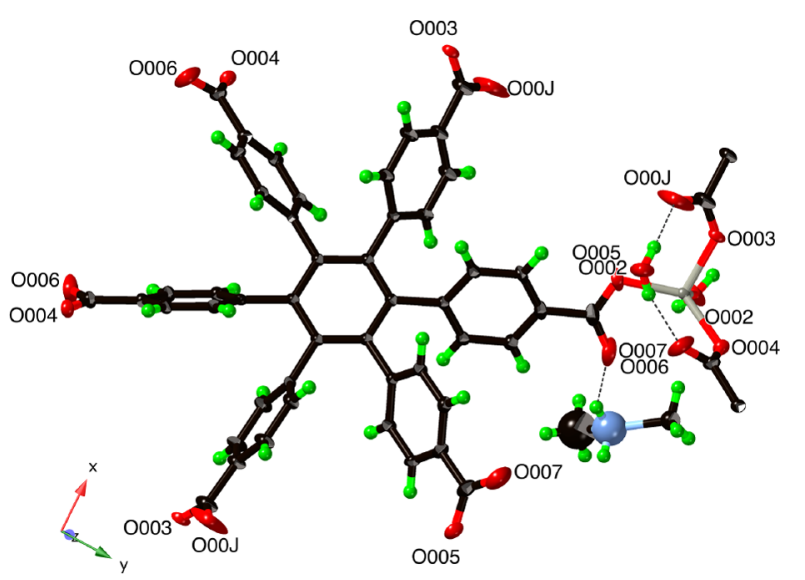

Figure 16. CTH-13 with ellipsoids drawn at 50\% probability. Water molecules hydrogen bond between the $\mathrm{Zn}$ (II) entities forming the yav-net (Figure 3).

Chirality Aspects. An important feature of network topology that is relevant to discuss here is chirality, as the $\mathrm{cpb}$ ligand with its distinct propeller shape (see Chart 1) is conformationally chiral. Conformationally chiral molecules are known to adopt chiral network topologies when they form conglomerates, but whether this is the driving force for conglomerate formation is an open question. ${ }^{41}$ Figures S39 and S40 reveal the extent of the propeller shape of the cpb core and of conglomerate formation of cpb-type compounds. Of the aforementioned 6- and $n$-connected nets there is only one, cys, that is intrinsically chiral. However, none of the hexagon-based nets we have found adopt this topology, and in all cases, we have seen both conformational enantiomers present in the structures.

One of the previously known cpb MOFs, the $\mathrm{Cu}$ (II)-based MOF-890 (CSD ref code AZAVUU), however, crystallizes in a Sohncke group $\left(P 22_{1} 2_{1}\right.$, a "chiral" space group) but with the nonchiral net htp. (The kgd-net like all 2D nets is nonchiral, as it has a mirror plane; however as we have seen, its molecular realization might be chiral.)

In terms of chirality, these versions of the kgd-net with trisbischelating octahedral metal centers share some features with the honeycomb (hcb) nets constructed from tris-oxalate coordination entities. ${ }^{24,25}$ The latter contain alternating $\Delta$ or 
$\Lambda$ enantiomers of the metal complexes, and in all examples of the kgd-net with tris-bischelating octahedral metal centers (MOF-888, CTH-7, CTH-10, Zn-MOF-888, CTH-11) we also in each layer see alternating clockwise propellers for the $\mathrm{cpb}$ ligand and anticlockwise for the likewise propeller-shaped metal complex (and vice versa). This is always matched by the opposite chirality in the next layer.

It does, however, mean that for these kgd-nets each sheet is chiral, and if one were to deposit a single layer on a surface, an enantiopure surface layer would be generated. This is illustrated in Figure 17.

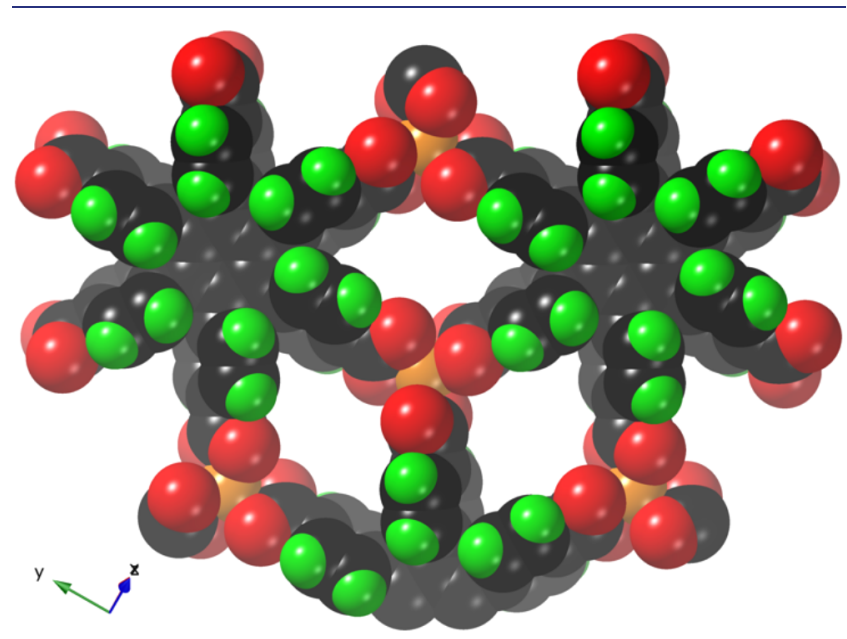

Figure 17. Chiral nature of a single layer kgd-net built from $\mathrm{cpb}$ ligands and octahedral metal entities exemplified by the crystal structure of CTH-7. Note that each metal entity is homochiral and each cpb ligand is present in one of the two conformation enantiomers only. Counterions are omitted for clarity.

Physical Properties of CTH-6 to CTH-13. Stability. (Supporting Information, Figures S5-S20) Thermal stability assessments of all MOFs in this study were performed using TGA up to $800{ }^{\circ} \mathrm{C}$ for all samples, and the thermal events are likewise interpreted in the Supporting Information. Powder Xray diffraction (PXRD) patterns of all MOFs, except for $\mathbf{Z n}$ MOF-888, CTH-11, and CTH-13, were recorded and compared. Complete data and comments for experimental, calculated, and post-gas-sorption PXRD patterns are also available. CTH-9 and CTH-12 were additionally characterized by collecting PXRD data at variable temperatures.

Gas Sorption Studies. Sorption experiments were carried out after pretreatment of the samples at $120^{\circ} \mathrm{C}$ for $6 \mathrm{~h}$ of dynamic vacuum. Permanent porosity for CTH-6 to CTH-12 was demonstrated by $\mathrm{N}_{2}$ adsorption isotherms at $-196{ }^{\circ} \mathrm{C}$ (Supporting Information, Figures S21-S38). The $S_{\mathrm{BET}}$ and $S_{\text {Lang }}$ for CTH-7, CTH-8, CTH-9, CTH-10, and CTH-12 were calculated and are listed in Table 2. CTH-6 was not deemed

Table 2. MOF Surface Area and $\mathrm{CO}_{2}$ and $\mathrm{N}_{2}$ Uptake

\begin{tabular}{ccccc} 
MOF & $\begin{array}{c}S_{\mathrm{BET}} \\
\left(\mathrm{m}^{2} \mathrm{~g}^{-1}\right)\end{array}$ & $\begin{array}{c}S_{\mathrm{Lang}} \\
\left(\mathrm{m}^{2} \mathrm{~g}^{-1}\right)\end{array}$ & $\begin{array}{c}\mathrm{N}_{2} \text { uptake } \\
\left(\mathrm{mmol} \mathrm{g}^{-1}\right)\end{array}$ & $\begin{array}{c}\mathrm{CO}_{2} \text { uptake } \\
\left(\mathrm{mmol} \mathrm{g}^{-1}\right)\end{array}$ \\
\hline CTH-7 & 126 & 155 & 0.062 & 0.533 \\
CTH-8 & 211 & 261 & 0.102 & 0.983 \\
CTH-9 & 301 & 374 & 0.069 & 0.733 \\
CTH-10 & 145 & 178 & 0.054 & 0.494 \\
CTH-12 & 34 & 42 & 0.064 & 1.209
\end{tabular}

pure enough to give unambiguous data, and Zn-MOF-888 was obtained together with CTH-11 (indicated earlier). As CTH-8 is isostructural to CTH-9, it is reasonable to expect their $S_{\mathrm{BET}}$ to be similar, as observed. Apart from the $S_{\mathrm{BET}}$ of CTH-12, the values are unremarkable.

Out of all the tested samples, CTH-12 has the highest $\mathrm{CO}_{2}$ uptake under the test conditions. The $\mathrm{CO}_{2}$-over- $\mathrm{N}_{2}$ selectivity (simply estimated by the $\mathrm{CO}_{2}$ uptake $/ \mathrm{N}_{2}$ uptake at $101 \mathrm{kPa}$ ) of CTH-12 was also the highest of all tested samples. The difference is a factor 19 rather than a factor 10 as is more normal and displayed by the other compounds in this study. Recently, dinuclear $\mathrm{Cu}$ (II) paddle-wheel coordination entities with free metal sites have been suggested to give a higher $\mathrm{CO}_{2}$ selectivity. ${ }^{42}$ We think a similar effect might explain the behavior of CTH-12 with some of the axially coordinated dmf molecules generating similar open sites during the pre-gassorption activation treatment. CTH-12 is the only compound in this study containing this kind of paddle-wheel motif.

Secondary Ion Mass Spectrometry. One of the major ideas of MOF and COF chemistry is to load the structure with compounds not present at synthesis; however, methods to investigate such postsynthetic modifications or diffusion added guests are scarce. We here highlight the possibilities of using ToF-SIMS in MOF research with some preliminary data on the sorption of iodine into CTH-7.

The choice to study $I_{2}$ sorption is foremost one of convenience. Iodine is easy to detect and not part of the framework, reagents, or solvents. There is, however, a potential application of $\mathrm{I}_{2}$ sorption because of the presence of the isotopes ${ }^{129} \mathrm{I}$ and ${ }^{131} \mathrm{I}$ in radioactive waste and in cases of nuclear accidents. New good sorption methods of iodine are needed, and MOFs are among the most promising materials investigated. $^{43}$

In the case of gases, it is straightforward to examine this by activating the MOF followed by the measurement of gas sorption isotherms. However, questions may remain about the amount of solvent still in the "activated" material, as very often the same MOF will give different surface area and void volume depending on the precise method of activation.

For MOFs that have been subject to postsynthetic modifications, it may be possible to obtain a crystal-to-crystal transformation and new single-crystal diffraction data, but this is not the normal case. The same is also true when interior solvent molecules are replaced by, for example, a molecular catalyst, in a diffusion process or by diffusion into an activated material. Questions arise whether subsequent catalysis takes place by active species on the surface or if the catalyst has entered into the material, and then how far and in which state.

The attraction of ToF-SIMS is that the ion beam can slowly dig into the material with a resolution of down to $100 \AA$, giving a depth profile of any species present in a crystal with the framework as a convenient internal standard. We note that the only reported SIMS studies on MOFs to date concern the identification of guest loading in thin films, not depth profiles. $^{44,45}$

The compound $2(\mathrm{Hdma})\left[\mathrm{Cu}_{2}(\mathrm{cpb})\right]$ (CTH-7) formed large uniformly shaped crystals, and the kgd-voids seemed to be good for fitting the $\mathrm{I}_{2}$ molecules with calculated voids of diameter $5.2 \AA$. As the experiment requires the crystals to be well visible in the SIMS microscope, they need to have a reasonable size $(0.1 \times 0.1 \mathrm{~mm})$, even though the probing area of the ion beam is smaller, typically down to $100 \times 100 \mathrm{~nm}$. 
Both $\mathrm{MeOH}$ solutions of $\mathrm{I}_{2}$ and direct $\mathrm{I}_{2}$ gas sorption by diffusion in a closed desiccator were tested. In both cases, $\mathrm{I}_{2}$ was shown to have penetrated into the crystals, detected as layers were consecutively peeled away by the ion beam. Figure 18 shows the relative counts of different secondary ions

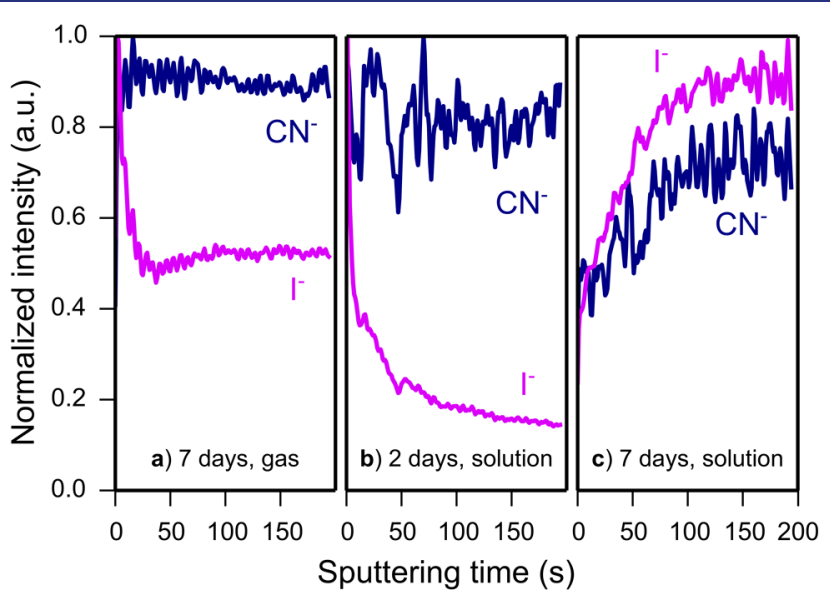

Figure 18. Time of flight secondary ion mass spectrometry (ToFSIMS) experiments on $2(\mathrm{Hdma})\left[\mathrm{Cu}_{2}(\mathrm{cpb})\right] \cdot 2 \mathrm{dmf}(\mathbf{C T H}-7)$ with (a) direct $\mathrm{I}_{2}$ gas sorption by diffusion in air in a closed desiccator and (b, c) $\mathrm{MeOH}$ solutions of $\mathrm{I}_{2}$. Sputter time is proportional to the depth probed in the crystal, and the $x$-scale corresponds to a depth of approximately $400 \AA$. The surface probe area is typically $4000 \times 4000$ $\AA$, rastered over a large area, typically $60 \mu \mathrm{m} \times 60 \mu \mathrm{m}$; thus the depth penetration is averaged over a large number of unit cells.

detected. We have taken cyanide ions (from dma or Hdma) as a measure of the framework contents, and we expect this count to be constant or perhaps to be lower close to the surface for the solution experiment, if dma has been replaced by $\mathrm{MeOH}$.

Penetration is lower for gas-phase and the shorter solution exposure time, while the longer solution exposure indicates saturation. In principle, gas-phase studies are to be preferred, as there are then no possibilities of dissolution and recrystallization of parts of the crystal.

The plot has sputter time instead of the more desirable length scale; however, to accomplish this requires additional measurements with an AFM microscope that could accurately measure the depth of the sputtered hole in order to establish the sputtering time versus depth relation for MOF-type materials. From measurements on other materials such as trehalose ${ }^{46}$ and $\mathrm{SiO}_{2}$ layer films, ${ }^{47}$ using a similar $\mathrm{C} 60$ setup we can, however, estimate that what we see in Figure 18 corresponds to a horizontal scale of around $400 \AA$.

\section{CONCLUSIONS}

We have extended reticular chemistry with two new ways of combining the hexagon with other geometrical figures, the trigonal pyramid in CTH-6 with the rtl-net in a new hexagon embedding, and the new laf-net with perfect hexagons and triangles, derived from purely geometrical considerations. This increases the "blueprints" available for hexagon network chemistry by almost $30 \%$.

Furthermore, we have introduced the concept of foldable network topologies and given examples of the basic polygons and their combinations. Likely, the most important foldable nets (highest symmetry) are ths (triangles), cds (squares), tfk (triangles and squares), laf (triangles and hexagons), and jem (squares and hexagons). We suggest the most prominent examples of breathing MOFs can be thought of having the cds topology, further explaining this behavior. Moreover, we suggest a new design strategy for breathing MOFs that is not based on rod-MOFs with infinite SBUs.

Finally, we have made the first attempt to obtain depth profiles of guest compounds sorbed into MOFs by ToF-SIMS, showing penetration of iodine $\left(\mathrm{I}_{2}\right)$ into $\mathrm{CTH}-7$ both from solution and from the gas phase.

\section{EXPERIMENTAL SECTION}

Materials and General Procedures. All chemicals utilized for MOF synthesis (details in the Supporting Information) were purchased from Sigma-Aldrich and were used without further purification. All MOF preparations have been performed repeatedly, and yields are in general high, close to quantitative with respect to the metal ion except for CTH-6, where the insolubility of $\mathrm{H}_{6} \mathrm{cpb}$ in solvents known to give high-yield Bi-MOFs prevented optimal conditions. No independent analysis was performed to confirm the presence of protonated dimethylamine, as the solvent $\mathrm{dmf}$ is easily hydrolyzed to dimethylamine and formic acid. These impurities are always present in dmf unless it is freshly purified and dry. The hydrolysis is particularly efficient under basic conditions but can also occur under acidic conditions, especially if catalyzed by metal ions or other Lewis acids. ${ }^{48}$ To date protonated dimethyl amine has been detected in over 600 MOF structures in the Cambridge Crystallographic Database. ${ }^{49}$ All studied MOF single crystals were washed and immersed in $\mathrm{dmf}$ before conducting single-crystal X-ray diffraction analysis to remove any unreacted $\mathrm{H}_{6} \mathrm{cpb}$.

Computational Tools. CrystalMaker was used for all structure drawings and porosity and cavity calculations. For the two latter calculations, van der Waals radii were used. CrystalMaker calculates empty volumes as the residual volume after atomic volumes have been subtracted from the total volume. For the size of cavities, CrystalMaker scans through the structure, aiming to find the largest sphere that can fit into any cavity using multiple iterations. ${ }^{50}$ Systre was used for topology analysis. ${ }^{17}$ The new laf-net was discovered by real-life model-building using an Orbit organic and inorganic chemistry model set. A model with several repeating units was constructed, and the unit cell, space group, and coordinates of the asymmetric unit were determined. Subsequently, these data were fed into the Systre program, and the most symmetric embedding of the net was determined. Systre input and output files are found in the Supporting Information. ToposPro and the TopCryst.com search routine were used to find examples of the laf-net. ${ }^{26}$

\section{ASSOCIATED CONTENT}

\section{Supporting Information}

The Supporting Information is available free of charge at https://pubs.acs.org/doi/10.1021/jacs.0c02984.

\section{Crystallographic data (CIF)}

Crystallographic data (CIF)

Crystallographic data (CIF)

Crystallographic data (CIF)

Crystallographic data (CIF)

Crystallographic data (CIF)

Crystallographic data (CIF)

Additional information (PDF)

\section{AUTHOR INFORMATION}

\section{Corresponding Authors}

Francoise M. Amombo Noa - Chemistry and Biochemistry, Department of Chemistry and Chemical Engineering, Chalmers University of Technology, SE-41296 Gothenburg, Sweden; 이이.org/0000-0001-8361-3432; Email: mystere@ chalmers.se 
Lars Öhrström - Chemistry and Biochemistry, Department of Chemistry and Chemical Engineering, Chalmers University of Technology, SE-41296 Gothenburg, Sweden; 이잉.org/ 0000-0002-6420-2141; Email: ohrstrom@chalmers.se

\section{Authors}

Erik Svensson Grape - Department of Materials and Environmental Chemistry, Stockholm University, Stockholm SE10691, Sweden; 이이.org/0000-0002-8956-5897

Steffen M. Brülls - Chemistry and Biochemistry, Department of Chemistry and Chemical Engineering, Chalmers University of Technology, SE-41296 Gothenburg, Sweden

Ocean Cheung - Nanotechnology and Functional Materials, Department of Materials Science and Engineering, Uppsala University, SE-751 21 Uppsala, Sweden; 이이.org/00000002-4072-4324

Per Malmberg - Chemistry and Biochemistry, Department of Chemistry and Chemical Engineering, Chalmers University of Technology, SE-41296 Gothenburg, Sweden; 이잉.org/ 0000-0002-6487-7851

A. Ken Inge - Department of Materials and Environmental Chemistry, Stockholm University, Stockholm SE-10691, Sweden; 이이이.org/0000-0001-9118-1342

Christine J. McKenzie - Department of Physics, Chemistry and Pharmacy, University of Southern Denmark, 5230 Odense M, Denmark; 이이.org/0000-0001-5587-0626

Jerker Martensson - Chemistry and Biochemistry, Department of Chemistry and Chemical Engineering, Chalmers University of Technology, SE-41296 Gothenburg, Sweden

Complete contact information is available at:

https://pubs.acs.org/10.1021/jacs.0c02984

\section{Notes}

The authors declare no competing financial interest.

\section{ACKNOWLEDGMENTS}

F.M.A.N. and L.Ö. are grateful to the Swedish Research Council (\#2017-04725). E.S.G. and A.K.I. acknowledge the Swedish Foundation for Strategic Research (SSF) and the Knut and Alice Wallenberg Foundation (KAW 2016.0072). O.C. acknowledges the Swedish Research Council for Sustainable Development (FORMAS, \#2018-00651) and the ÅForsk Foundation (\#19-549). C.J.M. is grateful to the Carlsberg Foundation for funding (grant CF15-0675) for the X-ray diffractometer. We thank Michael O'Keeffe for adding the laf-net to the RCSR and Dr. Christian Göb, Rigaku Europe SE, for assistance with the measurement of CTH-13.

\section{REFERENCES}

(1) Ockwig, N. W.; Delagado-Friedrichs, O.; O’Keeffe, M.; Yaghi, O. M. Reticular Chemistry: Occurrence and Taxonomy of Nets and Grammar for the Design of Frameworks. Acc. Chem. Res. 2005, 38 (3), $176-182$.

(2) Yaghi, O. M.; O'Keeffe, M.; Ockwig, N. W.; Chae, H. K.; Eddaoudi, M.; Kim, J. Reticular synthesis and the design of new materials. Nature 2003, 423 (6941), 705-714.

(3) Batten, S. R.; Champness, N. R.; Chen, X. M.; Garcia-Martinez, J.; Kitagawa, S.; Öhrström, L.; O’Keeffe, M.; Suh, M. P.; Reedijk, J. Terminology of Metal-Organic Frameworks and Coordination Polymers (IUPAC recommendations 2013). Pure Appl. Chem. 2013, 85 (8), 1715-1724.

(4) Yaghi, O. M.; Kalmutzki, M. J.; Diercks, C. S. Introduction to Reticular Chemistry - Metal-Organic Frameworks and Covalent Organic Frameworks; Wiley-VCH: Weinheim, 2019.
(5) Öhrström, L. Designing, Describing and Disseminating New Materials by using the Network Topology Approach. Chem. - Eur. J. 2016, 22 (39), 13758-13763.

(6) Öhrström, L.; O'Keeffe, M. Network topology approach to new allotropes of the group 14 elements. Z. Kristallogr. - Cryst. Mater. 2013, 228 (7), 343-346.

(7) Chung, Y. G.; Haldoupis, E.; Bucior, B. J.; Haranczyk, M.; Lee, S.; Zhang, H.; Vogiatzis, K. D.; Milisavljevic, M.; Ling, S.; Camp, J. S.; Slater, B.; Siepmann, J. I.; Sholl, D. S.; Snurr, R. Q. Advances, Updates, and Analytics for the Computation-Ready, Experimental Metal-Organic Framework Database: CoRE MOF 2019. J. Chem. Eng. Data 2019, 64 (12), 5985-5998.

(8) Barthel, S.; Alexandrov, E. V.; Proserpio, D. M.; Smit, B. Distinguishing Metal-Organic Frameworks. Cryst. Growth Des. 2018, 18 (3), 1738-1747.

(9) Collings, I. E.; Tucker, M. G.; Keen, D. A.; Goodwin, A. L. Geometric switching of linear to area negative thermal expansion in uniaxial metal-organic frameworks. CrystEngComm 2014, 16 (17), 3498-3506.

(10) Tan, J. C.; Bennett, T. D.; Cheetham, A. K. Chemical structure, network topology, and porosity effects on the mechanical properties of Zeolitic Imidazolate Frameworks. Proc. Natl. Acad. Sci. U. S. A. 2010, 107 (22), 9938-9943.

(11) Kalmutzki, M. J.; Hanikel, N.; Yaghi, O. M. Secondary building units as the turning point in the development of the reticular chemistry of MOFs. Sci. Adv. 2018, 4 (10), eaat9180.

(12) Wells, A. F. Three-Dimensional Nets and Polyhedra; John Wiley \& Sons: New York, 1977.

(13) Robson, R. A net-based approach to coordination polymers. Dalton Trans. 2000, 3735-3744.

(14) Koch, E.; Fischer, W. Sphere packings with three contacts per sphere and the problem of the least dense sphere packing. $Z$. Kristallogr. - Cryst. Mater. 1995, 210, 407-414.

(15) Delgado-Friedrichs, O.; O’Keeffe, M.; Yaghi, O. M. Threeperiodic nets and tilings: edge-transitive binodal structures. Acta Crystallogr., Sect. A: Found. Crystallogr. 2006, 62 (5), 350-355.

(16) Delgado-Friedrichs, O.; O’Keeffe, M. Three-periodic tilings and nets: face-transitive tilings and edge-transitive nets revisited. Acta Crystallogr., Sect. A: Found. Crystallogr. 2007, 63 (4), 344-347.

(17) Delgado-Friedrichs, O.; O’Keeffe, M. Identification and symmetry computation for crystal nets. Acta Crystallogr., Sect. A: Found. Crystallogr. 2003, 59, 351-360.

(18) O'Keeffe, M.; Peskov, M. A.; Ramsden, S.; Yaghi, O. M. The Reticular Chemistry Structure Resource (RCSR) Database of, and Symbols for, CrystalNets. Acc. Chem. Res. 2008, 41, 1782-1789.

(19) O'Keeffe, M.; Delgado-Friedrichs, O. Reticular Chemistry Structure Resource, 2019. http://rcsr.anu.edu.au/.

(20) Chen, Z.; Weseliński, Ł. J.; Adil, K.; Belmabkhout, Y.; Shkurenko, A.; Jiang, H.; Bhatt, P. M.; Guillerm, V.; Dauzon, E.; Xue, D.-X.; O'Keeffe, M.; Eddaoudi, M. Applying the Power of Reticular Chemistry to Finding the Missing alb-MOF Platform Based on the (6,12)-Coordinated Edge-Transitive Net. J. Am. Chem. Soc. 2017, 139 (8), 3265-3274.

(21) Chen, Z.; Li, P.; Wang, X.; Otake, K.-i.; Zhang, X.; Robison, L.; Atilgan, A.; Islamoglu, T.; Hall, M. G.; Peterson, G. W.; Stoddart, J. F.; Farha, O. K. Ligand-Directed Reticular Synthesis of Catalytically Active Missing Zirconium-Based Metal-Organic Frameworks. J. Am. Chem. Soc. 2019, 141 (31), 12229-12235.

(22) Chen, Z.; Thiam, Z.; Shkurenko, A.; Weselinski, L. J.; Adil, K.; Jiang, H.; Alezi, D.; Assen, A. H.; O’Keeffe, M.; Eddaoudi, M. Enriching the Reticular Chemistry Repertoire with Minimal EdgeTransitive Related Nets: Access to Highly Coordinated MetalOrganic Frameworks Based on Double Six-Membered Rings as NetCoded Building Units. J. Am. Chem. Soc. 2019, 141 (51), 2048020489.

(23) Nguyen, P. T. K.; Nguyen, H. T. D.; Pham, H. Q.; Kim, J.; Cordova, K. E.; Furukawa, H. Synthesis and Selective CO2 Capture Properties of a Series of Hexatopic Linker-Based Metal-Organic Frameworks. Inorg. Chem. 2015, 54 (20), 10065-10072. 
(24) Dazem, C. L. F.; Noa, F. M. A.; Nenwa, J.; Öhrström, L. R. Natural and synthetic metal oxalates - a topology approach. CrystEngComm 2019, 21, 6156-6164.

(25) Öhrström, L.; Larsson, K. What kinds of three-dimensional nets are possible with tris-chelated metal complexes as building blocks? Dalton Trans. 2004, No. 3, 347-353.

(26) Blatov, V. A.; Shevchenko, A. P.; Proserpio, D. M. Applied Topological Analysis of Crystal Structures with the Program Package ToposPro. Cryst. Growth Des. 2014, 14 (7), 3576-3586.

(27) Decurtins, S.; Schmalle, H. W.; Schneuwly, P.; Ensling, J.; Gütlich, P. A concept for the synthesis of 3-dimensional homo- and bimetallic oxalate-bridged networks $\left[\mathrm{M}_{2}(\mathrm{ox})_{3}\right]_{\mathrm{n}}$. Structural, mössbauer, and magnetic studies in the field of molecular-based magnets. J. Am. Chem. Soc. 1994, 116, 9521.

(28) Parent, L. R.; Pham, C. H.; Patterson, J. P.; Denny, M. S.; Cohen, S. M.; Gianneschi, N. C.; Paesani, F. Pore Breathing of Metal-Organic Frameworks by Environmental Transmission Electron Microscopy. J. Am. Chem. Soc. 2017, 139 (40), 13973-13976.

(29) Grape, E. S.; Xu, H.; Cheung, O.; Calmels, M.; Zhao, J.; Dejoie, C.; Proserpio, D. M.; Zou, X.; Inge, A. K. A Breathing Metal-Organic Framework Based on Flexible Inorganic Building Units. Cryst. Growth Des. 2020, 20, 320-329.

(30) Wang, Y.; Takki, S.; Cheung, O.; Xu, H.; Wan, W.; Öhrström, L.; Inge, A. K. Elucidation of the elusive structure and formula of the active pharmaceutical ingredient bismuth subgallate by continuous rotation electron diffraction. Chem. Commun. 2017, 53 (52), 70187021.

(31) Férey, G.; Serre, C. Large breathing effects in three-dimensional porous hybrid matter: facts, analyses, rules and consequences. Chem. Soc. Rev. 2009, 38 (5), 1380-1399.

(32) Schneemann, A.; Bon, V.; Schwedler, I.; Senkovska, I.; Kaskel, S.; Fischer, R. A. Flexible metal-organic frameworks. Chem. Soc. Rev. 2014, 43 (16), 6062-6096.

(33) Bon, V.; Kavoosi, N.; Senkovska, I.; Kaskel, S. Tolerance of Flexible MOFs toward Repeated Adsorption Stress. ACS Appl. Mater. Interfaces 2015, 7 (40), 22292-22300.

(34) Wei, Y.-S.; Chen, K.-J.; Liao, P.-Q.; Zhu, B.-Y.; Lin, R.-B.; Zhou, H.-L.; Wang, B.-Y.; Xue, W.; Zhang, J.-P.; Chen, X.-M. Turning on the flexibility of isoreticular porous coordination frameworks for drastically tunable framework breathing and thermal expansion. Chemical Science 2013, 4 (4), 1539-1546.

(35) Alexandrov, E. V.; Goltsev, A. V.; Eremin, R. A.; Blatov, V. A. Anisotropy of Elastic Properties of Metal-Organic Frameworks and the Breathing Phenomenon. J. Phys. Chem. C 2019, 123 (40), 2465124658.

(36) Mason, J. A.; Oktawiec, J.; Taylor, M. K.; Hudson, M. R.; Rodriguez, J.; Bachman, J. E.; Gonzalez, M. I.; Cervellino, A.; Guagliardi, A.; Brown, C. M.; Llewellyn, P. L.; Masciocchi, N.; Long, J. R. Methane storage in flexible metal-organic frameworks with intrinsic thermal management. Nature 2015, 527 (7578), 357-361.

(37) Rosi, N. L.; Kim, J.; Eddaoudi, M.; Chen, B.; O'Keeffe, M.; Yaghi, O. M. Rod Packings and Metal-Organic Frameworks Constructed from Rod-Shaped Secondary Building Units. J. Am. Chem. Soc. 2005, 127 (5), 1504-1518.

(38) Tshuma, P.; Makhubela, B. C. E.; Öhrström, L.; Bourne, S. A.; Chatterjee, N.; Beas, I. N.; Darkwa, J.; Mehlana, G. Cyclometalation of lanthanum(iii) based MOF for catalytic hydrogenation of carbon dioxide to formate. RSC Adv. 2020, 10 (6), 3593-3605.

(39) Wang, B.; Rhauderwiek, T.; Inge, A. K.; Xu, H.; Yang, T.; Huang, Z.; Stock, N.; Zou, X. A Porous Cobalt Tetraphosphonate Metal-Organic Framework: Accurate Structure and Guest Molecule Location Determined by Continuous-Rotation Electron Diffraction. Chem. - Eur. J. 2018, 24 (66), 17429-17433.

(40) Etter, M. C.; MacDonald, J. C.; Bernstein, J. Graph-set analysis of hydrogen-bond patterns in organic crystals. Acta Crystallogr., Sect. B: Struct. Sci. 1990, 46 (2), 256-262.

(41) Johnson, M. T.; Dzolic, Z.; Cetina, M.; Lahtinen, M.; Ahlquist, M. S. G.; Rissanen, K.; Öhrström, L.; Wendt, O. F. Preparation of potentially porous, chiral organometallic materials through sponta- neous resolution of pincer palladium conformers. Dalton Trans. 2013, 42, 8484-8491.

(42) Kochetygov, I.; Bulut, S.; Asgari, M.; Queen, W. L. Selective $\mathrm{CO} 2$ adsorption by a new metal-organic framework: synergy between open metal sites and a charged imidazolinium backbone. Dalton Trans. 2018, 47 (31), 10527-10535.

(43) Xie, W.; Cui, D.; Zhang, S.-R.; Xu, Y.-H.; Jiang, D.-L. Iodine capture in porous organic polymers and metal-organic frameworks materials. Mater. Horiz. 2019, 6 (8), 1571-1595.

(44) Baroni, N.; Turshatov, A.; Oldenburg, M.; Busko, D.; Adams, M.; Haldar, R.; Welle, A.; Redel, E.; Woll, C.; Richards, B. S.; Howard, I. A. Facile loading of thin-film surface-anchored metal-organic frameworks with Lewis-base guest molecules. Materials Chemistry Frontiers 2017, 1 (9), 1888-1894.

(45) So, M. C.; Beyzavi, M. H.; Sawhney, R.; Shekhah, O.; Eddaoudi, M.; Al-Juaid, S. S.; Hupp, J. T.; Farha, O. K. Post-assembly transformations of porphyrin-containing metal-organic framework (MOF) films fabricated via automated layer-by-layer coordination. Chem. Commun. 2015, 51 (1), 85-88.

(46) Wucher, A.; Cheng, J.; Winograd, N. Molecular Depth Profiling Using a C60 Cluster Beam: The Role of Impact Energy. J. Phys. Chem. C 2008, 112 (42), 16550-16555.

(47) Kobayashi, D.; Yamamoto, Y.; Isemura, T. Time-of-flight SIMS depth profiling of $\mathrm{Na}$ in $\mathrm{SiO} 2$ glass using $\mathrm{C} 60$ sputter ion beam. Surf. Interface Anal. 2013, 45 (1), 113-116.

(48) Juillard, J. Pure Appl. Chem. 1977, 49, 885-892.

(49) Groom, C. R.; Bruno, I. J.; Lightfoot, M. P.; Ward, S. C. The Cambridge Structural Database. Acta Crystallogr., Sect. B: Struct. Sci., Cryst. Eng. Mater. 2016, 72 (2), 171-179.

(50) Images and video generated using CrystalMaker: a crystal and molecular structures program for Mac and Windows. CrystalMaker Software Ltd: Oxford, England (www.crystalmaker.com), 2019. 